ITEJ Juli-2020, Volume 5 Nomor 2 Page 66 - 79

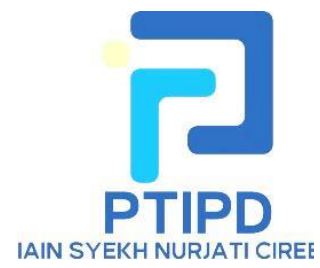

\author{
ITEJ \\ Information Technology Engineering Journals \\ eISSN : $\underline{2548-2157}$
}



Url : https://syekhnurjati.ac.id/journal/index.php/itej

Email : itej@syekhnurjati.ac.id

\title{
Acceptance of Technology in Online Learning Perspective at Educational Institutions : A Systematic Literature Review
}

\author{
Agus Pamuji \\ Islamic Counseling Guidance \\ State Islamic Institute of Sheikh Nurjati Cirebon \\ Cirebon, Indonesia \\ agus.pamuji@syekhnurjati.ac.id
}

\begin{abstract}
Today, many applications or technologies have been produced by every software developer. However, the success of all there is the decision of each user. Users have two possibilities to accept or reject a technology that is presented. The TAM model has been widely researched and undergone development and changes besides being quite reliable in predicting the level of technology acceptance in all countries in the world. In this study, we will recapitulate all studies on the acceptance of technology in the field of Education that handles online learning. The results showed that there was 51 article review publication were selected through some process of review. The period taken ranges from 2011 to 2020 . The main findings show that there are differences in the models, methods, and applications identified. Since the TAM model has two basic variables, namely perceived ease of use and perceived usefulness as a framework for analyzing the make and influence technology acceptance. In this study also provides information about the results of the identification of some of the gaps in current research and also in the future. Therefore, the results of a systematic literature review were able to provide a better understanding of TAM especially in the perspective of education in online learning.
\end{abstract}

Keywords - Systematic Review, Technology Acceptance, Online Learning, Applications, Methods

\section{INTRODUCTION}

Today almost the life of society flooded with a variety of information [1]. This information is essentially generated from technological devices[2]. Unwittingly been many changes - changes in addition to the development of the technology itself[3], [4]. One of them is in learning which is carried out using the online method. Given the increasing number of users together also with the progress of the technology so encouraging to be studied in its acceptance[5]. Technology acceptance model has been widely studied with various patterns of implementation[6]. In this context the various applications or systems used by the user[7]. Thus, the technology acceptance model has undergone many changes with the modification [8] results of several studies that are considered relevant. 
In this paper, a review will be carried out from a wide variety of literature. The literature relating to the assessment meant acceptance of the technology which was first proposed by the inventor Mr. TAM (Davis)[9]. In addition, this paper will classify and also summarize various types of technology acceptance models with the aim of providing a comprehensive overview of the technology acceptance models in addition to measuring the level of effectiveness[10]. But so far the systematic reviews that have been carried out by researchers are only as a guide and also a report as a reference for the study of technology acceptance models[11],[12],[13]. In line that, the first step in this literature review is to determine the scope of the topic to decide whether the study is relevant or not. In this paper we plan the structure of the article collection in an attempt to review what is produced and identify the core of current knowledge[14]. However, this paper may still be incomplete, without a systematic procedure, extracting insufficient knowledge.

There are various applications or systems used in higher education. Even though all of that is still the same in the concept of learning electronically and also online. Starting from the core applications as e-learning, zoom, video conferencing, social media and so on[15]. Almost all activities involve applications[16]. But so far, existing research has only discussed one item, for example e-learning, while this concept is not only one application but more[17]. On another occasion, in an effort to support the systematic review process, we determined data sources to be used as data collections[18]. All data is collected from various journal sources or websites as well as a database system that contains online journal information[19]. Furthermore, each article will be selected selectively and in detail related to the topic being studied[20],[21]. The aim is to assist researchers in determining and using a broader range of specific research data sets. Journals or articles as data will be selected relating to the development and change of technology acceptance models. The timeframe or period as a feature of search for published research is taken between 2011 - 2020. The use of a systematic review framework is aimed at systematically identifying journals that in each process follow established steps, procedures, mechanisms or protocols. A systematic review framework can reduce the risk of identification that is not objective or even biased. Furthermore, it is intended that the identification results can increase the amount of literature on the application of a systematic review framework when assessing technology acceptance models.

\section{RESEARCH METHOD}

Systematic Literature Review is considered by researchers as a term adopted to refer to a particular research or research methodology[22]. Its development is carried out in gathering and evaluating related research on a particular topic focus[23],[24]. This research is carried out for various purposes[25], including identifying, studying[26], evaluating, and interpreting almost all available research with the topic area of the phenomenon of interest, with certain relevant research questions[27]. Besides that, it is often needed as a research agenda determination, part of a dissertation or thesis, and is a part that complements the substantive requirements for research grant applications[28],[29].

\section{A. Research Object}

The object of this research is the technology acceptance model. Making technology acceptance model as the research object has several considerations including: First, the change in technology acceptance model over the last decade. Second, changes, development, and modification of technology acceptance models, there are several construct variables, both endogenous and exogenous. Third, the diversity of cases that have been investigated through the technology acceptance model in previous studies. 


\section{B. Research Questions}

In this context, there are research questions that are made based on the needs of the selected topic[30]. We conducted systematic reviews [31] of various approaches to evaluate that have been applied in the empirical literature on educational technology at the tertiary level[32]. Thus, it can support researchers to be more accurate so that the evaluation of the use of educational technology is more effective[33]. This paper focuses on how to evaluate the level of technology acceptance in education[34].

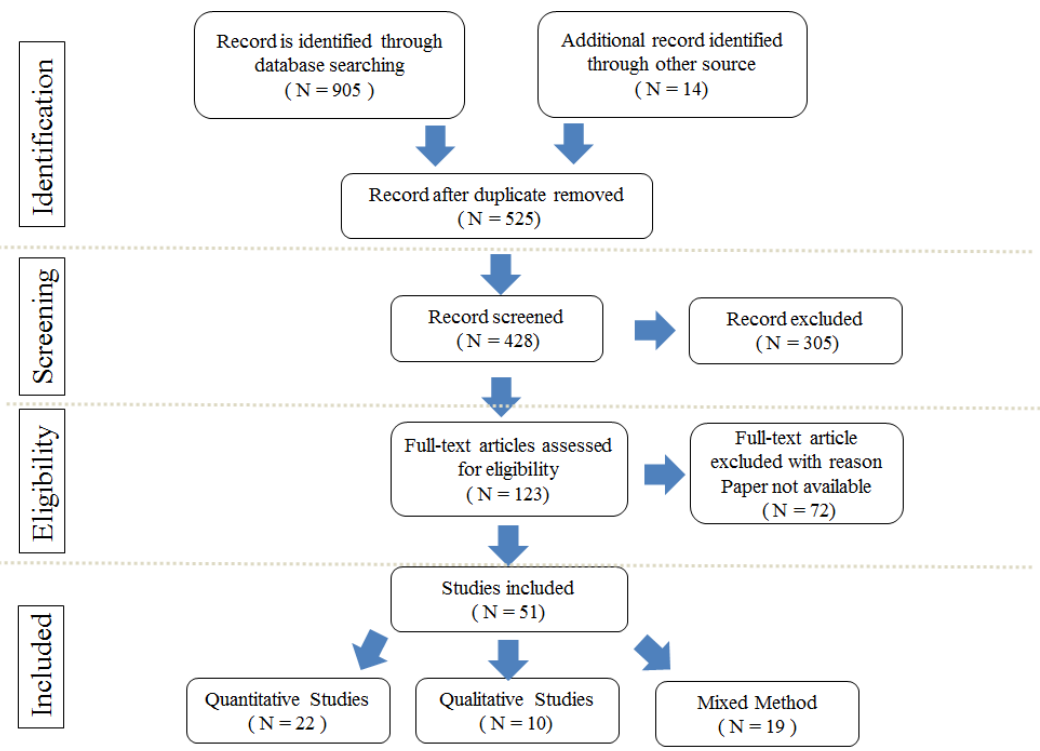

Figure 1. Systematic Review Process

RQ1 Does the technology acceptance analysis framework start from 2011 - 2020?

RQ2 What applications or technologies are often used in learning media?

RQ3 What methods are tested when evaluating technology acceptance in instructional media?

\section{The process of search, Inclusion and Exclusion Criteria}

The search process, as a support for systematic review, is used to obtain sources that are considered relevant in answering research questions and other related references. The search process is carried out using serach engine assistance tools such as direct science, springer link, google scholar, IEEE Explore and so on, marked as the primary data source (primary) and other search engines, namely www.google.com as supporting data (secondary)[35].

There are two stages, namely inclusion and exclusion criteria[36], where this stage is carried out to decide whether the data found in research uses a systematic literature review framework or not[37]. The rest, the study is feasible to choose if there are criteria including: source data used in this study is used in the time span between 2011 and 2020[38]. Second, the data obtained with the help of search engines such as science direct, Springer link, google scholar, IEEE Explore and www. google.com. Third, the source data used in this study only relates to the technology acceptance model.

\section{Evaluation and Data Collection}

The next stage, in evaluating the data that has been found through a search process based on the question of quality assessment criteria[39],[40],[41]. First, RQ1 was a journal paper or other similar published in 2011 - 2020? Second, RQ2 does the journal paper mention the application or system used in analyzing technology acceptance[42]. Finally, which methods are often used in analyzing technology acceptance[43],[44]. 
Data collection is a stage where data for research is collected. There are two types of data collected, namely primary data (primary) and supporting data (secondary). Primary data (primary) is intended as information collected through offline or online surveys, observations, and tailored to needs. In this study, the primary data obtained came from journals indexed or recorded in science direct, Springer Link, Google Scholar, and IEEE Explore. With this in mind, the serach engine facility provides complete, accurate and updated features. In addition, information is easy to find because it has a time range or period that can be adjusted based on the needs of the researcher[45]. The next data source is supporting data (secondary) which plays a role in completing the primary (primary) data. We use www.google.com to obtain supporting (secondary) data. Therefore, data collection in research is obtained through several stages, namely observation as a stage of data collection through direct observation to sources, namely direct science, Springer Link, Google Scholar, and IEEE Explore[46]. Next is a literature study which is a stage for conducting a data assessment study related to the systematic literature review method on journals that are retrieved through science direct, springer links, google scholar, and IEEE Explore.

Table 1. Summary of Search Result Based on Database

\begin{tabular}{lccc}
\hline Database Name & Search results & Duplicate Papers & Relevant Paper \\
\hline Science Direct & 68 & 30 & 5 \\
\hline IEEE Explorer & 182 & 167 & 3 \\
\hline Springer & 534 & 236 & 26 \\
\hline Google Scholar & 135 & 92 & 17 \\
\hline Total & 919 & 525 & 51 \\
\hline
\end{tabular}

\section{E. Analysis of Data Sources}

The data analysis stage is needed to show the technology acceptance analysis starting from 2011 - 2020 which refers to RQ1. What applications are often used in instructional media refers to RQ2, and what methods are tested when evaluating technology acceptance in education refers to RQ3. The final stage is the identification of the existence of report deviations (Deviation from Protocol) as a result of the study by showing the changes, namely:

1. This study identifies the analysis of technology acceptance, applications used in learning, and construct variables and answers the research questions that have been asked.

2. Collecting journal manuscripts or the like in answering and ensuring quality and providing information deemed mandatory.

3. Increase and expand the scope of the description of the systematic literature review framework in this study.

\section{RESULT}

\section{A. Overall Review of Selected Studies}

The first discussion, considering that all paper data have been selected, there are 51 articles that are considered original. The main choice is in the educational context when adopting technology as a learning tool[47],[48]. For the rest, we will concentrate on the publication history by researchers relating to the acceptance of technology as a defined topic[49],[50],[51],[52]. The picture below, illustrates that during the last 10 years, there have been several published research articles that were selected according to the criteria. Information about real trending starts from 2011 to 2020. There are a number of articles that were selected the highest in 2018 with 11 articles, while in 2012 the lowest was with an average of 5 to 6 published articles[53]. 
A further problem associated with the prevalence of author and researcher scattered around the world that focus on research on technology acceptance. This is particularly so on the perspective of learning, teaching, addressing various domains of learning and technology[54]. The image below can actually provide a visualization of a location or area that is different from the others.

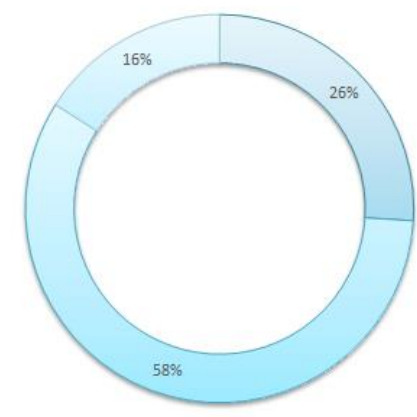

GOriginal TAM GExtended TAM Modified TAM

Figure 2. Summary of TAM Modeling and versions

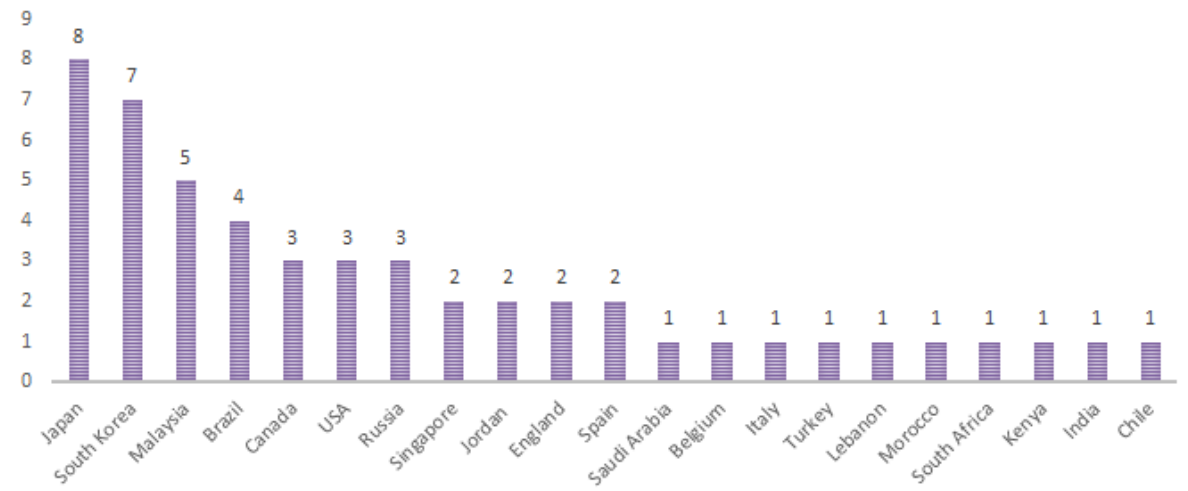

Figure 3. Contributions Paper From every country studies TAM

This topic was raised with the aim of studying the user's acceptance of technology when learning and to understand their behavior. Understand behavior when using all kinds of new information technologies and related technologies that can be used to support learning, teaching and assessment processes. Almost the majority of research on the concept of TAM in the context of education comes from Asia, especially developing countries in the Southeast and East Asian regions such as Malaysia, Thailand, Singapore, South Korea and Japan. However, followed by the second rank of countries in the western hemisphere such as Germany, Finland, France and Austria. Furthermore, there are in the Middle East, Africa, North America, and South America. Even though the numbers differ from each country, they have the same mission on how to improve the quality and experience in the learning process with the help of technology.

RQ1 Does the technology acceptance analysis framework start from 2011 - $2020 ?$

Based on the search results using strings as keywords, there are 905 published articles along with 14 additional articles. As for almost all documents or articles related to technology acceptance. Furthermore, we identified that there were 525 articles declared duplicates which provided the next step in screening, in fact there were 305 that 
succeeded in accordance with the criteria. If you look at the eligibility, there are 123 and so on until you get 51 data.

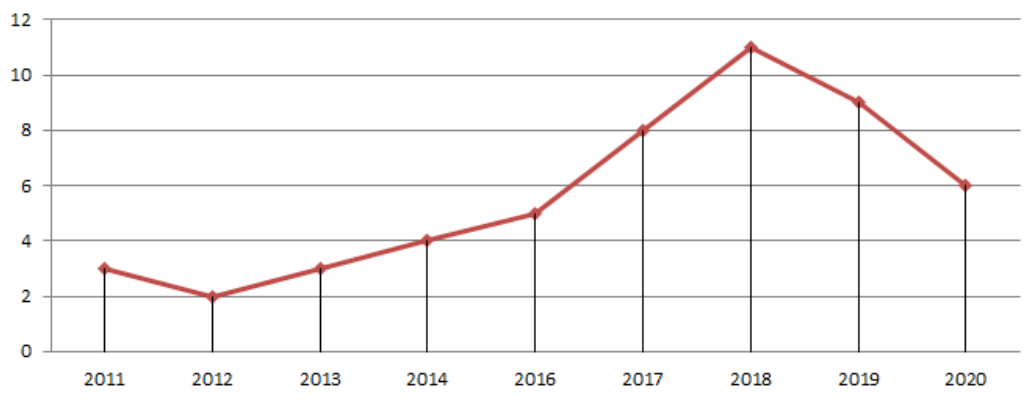

Figure 4. A collection of published articles after being selected by year

We found and identified it based on the year of publication taken from $2011-2020$. The highest number of figures was in 2018, namely $10-12$. This condition is considering that TAM has reliability and is increasingly trendy among researchers when assessing technology acceptance.

RQ2 What applications or technologies are often used in learning media?

It is unique in the study of objects in the form of TAM is the application or technology other than the user who adopt it. Many technologies have been used in learning with the aim of improving the quality of the learning process. The online-book media is the number that dominates the various literatures in addition to the perceived ease of using and studying the content contained therein. In second place, namely e-learning applications which are considered as the main needs when interacting with technology in connecting everyone.

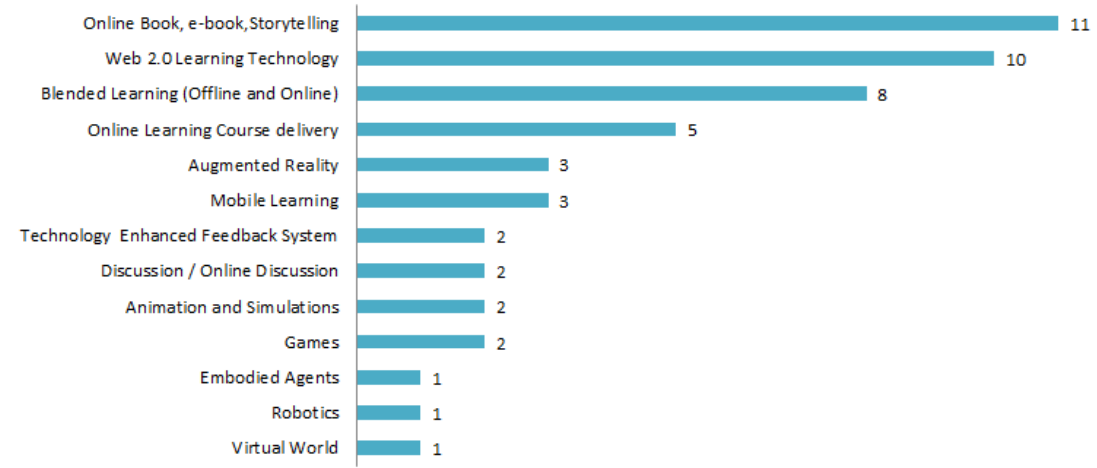

Figure 5. Learning technology used in educational institutions.

$R Q 3$ What methods are tested when evaluating technology acceptance in instructional media?

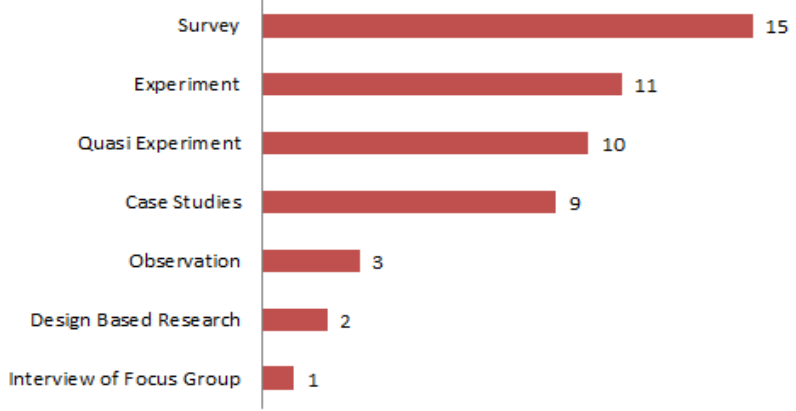


Figure 6. Summary of analysis methods for the study of technology acceptance models

Initially, we suspected that almost all of the research that had been carried out used experimental methods, but it turned out to be a survey. Thus, the survey is not only considered a way of collecting data but also as a method of analysis in statistical tests using a survey. Each user is given a Likert scale form when filling out the questionnaire.

\section{B. Gaps in Current Work and Implications for Future Research}

We are aware of the fact that in general, empirical research, although carefully designed and carried out, has opportunities for weaknesses that open new avenues for future work [55],[56]. Most of the studies presented in this systematic have pointed out some research gaps and hence have suggested there are areas or areas for further investigation. For example, most studies have cited generalization as a major drawback[57],[58]. Generalization for populations other than those in the study sample presented is discouraged due to specific demographic or cultural contexts. The data analyzed often comes from one or only a few educational institutions on the one hand and / or the sample of participants is too small [59]for any valid statistical analysis[60].

In addition, another general limitation applies to the short time period during which the research is conducted as well as with some new research variables based on TAM[61]. In line with the limitations presented, future research perspectives include new studies that include a wider sample of participants in particular other countries or other constructs, subjects and participants of different ages, circumstances or other e-learning infrastructure or broader technological tools[62]. In order to ensure the generalizability of the study findings, $[\mathrm{x}]$ has discussed that in subsequent studies, the findings should be validated in other settings beyond specific conditions such as subject characteristics and type[63].

In an effort to shorten, future studies could be extended to a large number of respondents to also include instructors because, apart from students, various teaching staff are also involved in the teaching and learning process[64]. In addition, future research needs to collaborate with the proposed method with a computational approach, for example using fuzzy logic or creating a decision support system. This alternative approach may be considered difficult but in the future all research results can be measured with certainty with the help and improvisation of computational theory in addition to using statistical analysis. Finally, several authors as well as researchers suggest training and socialization on how to use effective resources such as digital games as a learning tool and social media in the context of education.

\section{Limitations of The Conducted Review and Directions of Our Future Work}

In essence, the systematic study undertaken seeks to convey an important recapitulation of technology acceptance, especially concerning the field of education. In addition, it provides a critical picture of the state of the search effort. There are several considerations of limitations that must be considered. First, some concerns about the search keywords being specified can be raised[65]. Thus, it can be argued that a particular search term in a publication title does not completely cover all potentially contributing research studies.

This is because there are several peer-reviewed publications where these keywords may not appear in the title but still appear in the content. However, due to the considerable effort by researchers in the field of technology acceptance, the review cannot be considered complete but only includes representative academic literature.

Second, the potential specification of another criterion, namely the search term, together with other database options, may have resulted in more publications. Third, we start with the assumption that all extensions or modifications to the original TAM model will be adhered to under the generic term "TAM ++". However, during the final literature 
selection analysis, we realized that "TAM $++"$ was not a concrete term in the literature and continued to define the publication with a delivered research model based on the original TAM or modified or extended TAM. As there are gaps in current research as well as the limitations of the review itself, future research will follow new research directions:

- In order to search wider academic literature that will adopt several different keyword searches also included a special learning technologies as explicit search terms,

- Searches oriented discover and analyze the extension / modification new TAM, for example MTAM - cellular technology or STAM - social networking platform, GTAM GPS Technology.

- Implementation of studies to address some of the gaps identified in the current situation as a basis for seeking TAM in an educational context.

\section{CONCLUSION}

Without realizing it, currently living in an era of sophisticated technology that has the potential to have an impact on life in various ways. The existence of a configuration in the field of education has been recognized and is considered a domain with good potential. Thus it is able to adapt to new technology. It involves a wide range of learning technologies supporting the transfer process, transfer and acquisition of specific knowledge. Therefore, research examining the acceptance of technology in the field of teaching and learning has become an interesting and unique trend. TAM and its many versions are recognized in many countries around the world as a robust framework when planning and implementing empirical research in education. The work presented in a systematic review of the academic literature analyzing with TAM in the context of education brings a number of 51 basic studies published between 2011 and 2020 period. The studies that have been identified, assessed and analyzed offer various kinds of trials of studying technology with different research methods using TAM so that they seek to dig more and more about this important topic. The main findings are discussed and a summary of the gaps identified.

In the present study along with future research perspectives are presented. In general, the authors try to prove TAM as a reliable model for predicting the acceptance and use of various types of technology, especially learning. A new expansion / modification of the Model is proposed to cover various factors that influence the decision to adopt and accept or reject certain technologies in the teaching and learning process.

\section{ACKNOWLEDGEMENT}

In this research project is not funded or received grants by any institution.

\section{REFERENCES}

[1] Stal J., Paliwoda-Pękosz G. (2019) Mobile Technology Acceptance Model: An Empirical Study on Users' Acceptance and Usage of Mobile Technology for Knowledge Providing. In: Themistocleous M., Rupino da Cunha P. (eds) Information Systems. EMCIS 2018. Lecture Notes in Business Information Processing, vol 341. Springer, Cham. https://doi.org/10.1007/978-3-030-113957_42

[2] Tarmuji N.H., Ahmad S., Abdullah N.H.M., Nassir A.A., Idris A.S. (2019) Perceived Resources and Technology Acceptance Model (PRATAM): Students' Acceptance of e-Learning in Mathematics. In: Mohamad Noor M., Ahmad B., Ismail M., Hashim H., Abdullah Baharum M. (eds) Proceedings of the Regional Conference on Science, Technology and Social Sciences (RCSTSS 2016). Springer, Singapore. https://doi.org/10.1007/978-981-13-0203-9 13 
[3] Eltayeb M., Dawson M. (2016) Understanding User's Acceptance of Personal Cloud Computing: Using the Technology Acceptance Model. In: Latifi S. (eds) Information Technology: New Generations. Advances in Intelligent Systems and Computing, vol 448. Springer, Cham. https://doi.org/10.1007/978-3-319-324678_1

[4] Swilley E., Goldsmith R.E. (2015) Assessing the Impact of Corporate Credibility and Technology Acceptance on Online Shopping. In: Spotts H. (eds) Marketing, Technology and Customer Commitment in the New Economy. Developments in Marketing Science: Proceedings of the Academy of Marketing Science. Springer, Cham. https://doi.org/10.1007/978-3-319-11779-9_6

[5] Seuwou P., Banissi E., Ubakanma G. (2016) User Acceptance of Information Technology: A Critical Review of Technology Acceptance Models and the Decision to Invest in Information Security. In: Jahankhani H. et al. (eds) Global Security, Safety and Sustainability - The Security Challenges of the Connected World. ICGS3 2017. Communications in Computer and Information Science, vol 630. Springer, Cham. https://doi.org/10.1007/978-3-319-51064-4_19

[6] Nistor N., Weinberger A., Ceobanu C., Heymann J.O. (2011) Educational Technology and Culture: The Influence of Ethnic and Professional Culture on Learners' Technology Acceptance. In: Kloos C.D., Gillet D., Crespo García R.M., Wild F., Wolpers M. (eds) Towards Ubiquitous Learning. EC-TEL 2011. Lecture Notes in Computer Science, vol 6964. Springer, Berlin, Heidelberg. https://doi.org/10.1007/978-3-642-23985-4_42

[7] Ayeh J.K., Au N., Law R. (2013) Towards an Understanding of Online Travellers' Acceptance of Consumer-Generated Media for Travel Planning: Integrating Technology Acceptance and Source Credibility Factors. In: Cantoni L., Xiang Z. (eds) Information and Communication Technologies in Tourism 2013. Springer, Berlin, Heidelberg. https://doi.org/10.1007/978-3-642-36309-2_22

[8] Park, E., Kim, K.J. Driver acceptance of car navigation systems: integration of locational accuracy, processing speed, and service and display quality with technology acceptance model. Pers Ubiquit Comput 18, 503-513 (2014). https://doi.org/10.1007/s00779-013-0670-2

[9] Dirks S., Bühler C. (2018) Assistive Technologies for People with Cognitive Impairments - Which Factors Influence Technology Acceptance?. In: Antona M., Stephanidis C. (eds) Universal Access in Human-Computer Interaction. Methods, Technologies, and Users. UAHCI 2018. Lecture Notes in Computer Science, vol 10907. Springer, Cham. https://doi.org/10.1007/978-3-319-92049-8_36

[10] El-Masri, M., Tarhini, A. Erratum to: Factors affecting the adoption of e-learning systems in Qatar and USA: Extending the Unified Theory of Acceptance and Use of Technology 2 (UTAUT2). Education Tech Research Dev 65, 765-767 (2017). https://doi.org/10.1007/s11423-017-9526-1

[11] Ghazizadeh, M., Lee, J.D. \& Boyle, L.N. Extending the Technology Acceptance Model to assess automation. Cogn Tech Work 14, 39-49 (2012). https://doi.org/10.1007/s10111-011-0194-3

[12] Q. Al-Maatouk, M. S. Othman, A. Aldraiweesh, U. Alturki, W. M. Al-Rahmi and A. A. Aljeraiwi, "Task-Technology Fit and Technology Acceptance Model Application to Structure and Evaluate the Adoption of Social Media in Academia," in IEEE Access, vol. 8, pp. 78427-78440, 2020.doi: 10.1109

[13] M. Kuciapski, "How the Type of Job Position Influences Technology Acceptance: A Study of Employees' Intention to Use Mobile Technologies for Knowledge Transfer," in IEEE Access, vol. 7, pp. 177397-177413, 2019.doi: 10.1109/

[14] E. Park, Y. Cho, J. Han and S. J. Kwon, "Comprehensive Approaches to User Acceptance of Internet of Things in a Smart Home Environment," in IEEE Internet 
of Things Journal, vol. 4, no. 6, pp. 2342-2350, Dec. 2017. doi: 10.1109/JIOT.2017.2750765

[15] Y. H. Kwak, J. Park, B. Y. Chung and S. Ghosh, "Understanding End-Users' Acceptance of Enterprise Resource Planning (ERP) System in Project-Based Sectors," in IEEE Transactions on Engineering Management, vol. 59, no. 2, pp. 266-277, May 2012.doi: 10.1109/TEM.2011.2111456

[16] J. Y. L. Thong, V. Venkatesh, X. Xu, S. Hong and K. Y. Tam, "Consumer Acceptance of Personal Information and Communication Technology Services," in IEEE Transactions on Engineering Management, vol. 58, no. 4, pp. 613-625, Nov. 2011.doi: 10.1109/TEM.2010.2058851

[17] Teo T. (2011) Technology Acceptance Research in Education. In: Teo T. (eds) Technology Acceptance in Education. SensePublishers. https://doi.org/10.1007/978-94-6091-487-4_1

[18] Huang YM., Liu CH., Huang YM., Yeh YH. (2014) Adopt Technology Acceptance Model to Analyze Factors Influencing Students' Intention on Using a Disaster Prevention Education System. In: Huang YM., Chao HC., Deng DJ., Park J. (eds) Advanced Technologies, Embedded and Multimedia for Human-centric Computing. Lecture Notes in Electrical Engineering, vol 260. Springer, Dordrecht. https://doi.org/10.1007/978-94-007-7262-5_23

[19] Siyam, N. Factors impacting special education teachers' acceptance and actual use of technology. Educ Inf Technol 24, 2035-2057 (2019). https://doi.org/10.1007/s10639-018-09859-y

[20] Prietch S.S., Filgueiras L.V.L. (2015) Technology Acceptance Evaluation by Deaf Students Considering the Inclusive Education Context. In: Abascal J., Barbosa S., Fetter M., Gross T., Palanque P., Winckler M. (eds) Human-Computer Interaction - INTERACT 2015. INTERACT 2015. Lecture Notes in Computer Science, vol 9296. Springer, Cham. https://doi.org/10.1007/978-3-319-22701-6_2

[21] Dumpit, D.Z., Fernandez, C.J. Analysis of the use of social media in Higher Education Institutions (HEIs) using the Technology Acceptance Model. Int J Educ Technol High Educ 14, 5 (2017). https://doi.org/10.1186/s41239-017-0045-2

[22] Efiloğlu Kurt, Ö., Tingöy, Ö. The acceptance and use of a virtual learning environment in higher education: an empirical study in Turkey, and the UK. Int J Educ Technol High Educ 14, 26 (2017). https://doi.org/10.1186/s41239-017-0064$\mathrm{Z}$

[23] Chen, K.TC. Examining EFL instructors' and students' perceptions and acceptance toward M-learning in higher education. Univ Access Inf Soc 16, 967976 (2017). https://doi.org/10.1007/s10209-016-0494-8

[24] Wong K., Wang F.L., Ng K.K., Kwan R. (2015) Investigating Acceptance towards Mobile Learning in Higher Education Students. In: Li K.C., Wong TL., Cheung S.K.S., Lam J., Ng K.K. (eds) Technology in Education. Transforming Educational Practices with Technology. Communications in Computer and Information Science, vol 494. Springer, Berlin, Heidelberg. https://doi.org/10.1007/978-3-662-46158-7_2

[25] Kuciapski M. (2016) Students Acceptance of m-Learning for Higher Education UTAUT Model Validation. In: Wrycza S. (eds) Information Systems: Development, Research, Applications, Education. SIGSAND/PLAIS 2016. Lecture Notes in Business Information Processing, vol 264. Springer, Cham. https://doi.org/10.1007/978-3-319-46642-2_11

[26] Teo, T., Khlaisang, J., Thammetar, T. et al. A survey of pre-service teachers' acceptance of technology in Thailand. Asia Pacific Educ. Rev. 15, 609-616 (2014). https://doi.org/10.1007/s12564-014-9348-3

[27] Conti, D., Di Nuovo, S., Buono, S. et al. Robots in Education and Care of Children with Developmental Disabilities: A Study on Acceptance by Experienced 
and Future Professionals. Int $J$ of Soc Robotics 9, 51-62 (2017). https://doi.org/10.1007/s12369-016-0359-6

[28] García Botero, G., Questier, F., Cincinnato, S. et al. Acceptance and usage of mobile assisted language learning by higher education students. J Comput High Educ 30, 426-451 (2018). https://doi.org/10.1007/s12528-018-9177-1

[29] Luk CH., Ng KK., Lam WM. (2018) The Acceptance of Using Open-Source Learning Platform (Moodle) for Learning in Hong Kong's Higher Education. In: Cheung S., Lam J., Li K., Au O., Ma W., Ho W. (eds) Technology in Education. Innovative Solutions and Practices. ICTE 2018. Communications in Computer and Information Science, vol 843. Springer, Singapore. https://doi.org/10.1007/978981-13-0008-0_23

[30] Sakurai Y. (2014) The Value Improvement in Education Service by Grasping the Value Acceptance State with ICT Utilized Education Environment. In: Yamamoto S. (eds) Human Interface and the Management of Information. Information and Knowledge in Applications and Services. HIMI 2014. Lecture Notes in Computer Science, vol 8522. Springer, Cham. https://doi.org/10.1007/978-3-319-07863$2 \_10$

[31] Khalika Banda C., Gombachika H. (2013) Mobile Phone Technology Acceptance and Usability in the Delivery of Health Services among Health Surveillance Assistants in Rural Areas of Malawi. In: Jonas K., Rai I.A., Tchuente M. (eds) eInfrastructure and e-Services for Developing Countries. AFRICOMM 2012. Lecture Notes of the Institute for Computer Sciences, Social Informatics and Telecommunications Engineering, vol 119. Springer, Berlin, Heidelberg. https://doi.org/10.1007/978-3-642-41178-6_26

[32] Chu R., Li Y., Lai I.K.W., Zhu Z. (2014) Factors Influencing Trust and Acceptance of Electronic Sand Tables for Higher Business Education. In: Cheung S.K.S., Fong J., Zhang J., Kwan R., Kwok L.F. (eds) Hybrid Learning. Theory and Practice. ICHL 2014. Lecture Notes in Computer Science, vol 8595. Springer, Cham. https://doi.org/10.1007/978-3-319-08961-4_16

[33] Lakhal, S., Khechine, H. Relating personality (Big Five) to the core constructs of the Unified Theory of Acceptance and Use of Technology. J. Comput. Educ. 4, 251-282 (2017). https://doi.org/10.1007/s40692-017-0086-5

[34] Parkman, S., Litz, D. \& Gromik, N. Examining pre-service teachers' acceptance of technology-rich learning environments: A UAE case study. Educ Inf Technol 23, 1253-1275 (2018). https://doi.org/10.1007/s10639-017-9665-3

[35] Nkenke, E., Vairaktaris, E., Bauersachs, A. et al. Acceptance of technologyenhanced learning for a theoretical radiological science course: a randomized controlled trial. BMC Med Educ 12, 18 (2012). https://doi.org/10.1186/14726920-12-18

[36] Ahmed, E., Ward, R. A comparison of competing technology acceptance models to explore personal, academic and professional portfolio acceptance behaviour. J. Comput. Educ. 3, 169-191 (2016). https://doi.org/10.1007/s40692-016-0058-1

[37] Niehaves, B., Plattfaut, R. Internet adoption by the elderly: employing IS technology acceptance theories for understanding the age-related digital divide. Eur J Inf Syst 23, 708-726 (2014). https://doi.org/10.1057/ejis.2013.19

[38] Mohd Amir R.I., Mohd I.H., Saad S., Abu Seman S.A., Tuan Besar T.B.H. (2020) Perceived Ease of Use, Perceived Usefulness, and Behavioral Intention: The Acceptance of Crowdsourcing Platform by Using Technology Acceptance Model (TAM). In: Kaur N., Ahmad M. (eds) Charting a Sustainable Future of ASEAN in Business and Social Sciences. Springer, Singapore. https://doi.org/10.1007/978981-15-3859-9_34

[39] Ibili, E., Resnyansky, D. \& Billinghurst, M. Applying the technology acceptance model to understand maths teachers' perceptions towards an augmented reality 
tutoring system. Educ Inf Technol 24, 2653-2675 (2019). https://doi.org/10.1007/s10639-019-09925-z

[40] Tulinayo, F., Ssentume, P. \& Najjuma, R. Digital technologies in resource constrained higher institutions of learning: a study on students' acceptance and usability. Int $\mathrm{J}$ Educ Technol High Educ 15, 36 (2018). https://doi.org/10.1186/s41239-018-0117-y

[41] Brennan B. (2016) Mandatory Continuing Professional Education - Its Origin and Acceptance. In: Continuing Professional Education in Australia. Springer, Singapore. https://doi.org/10.1007/978-981-10-1832-9_4

[42] Shen, Cw., Ho, Jt., Ly, P.T.M. et al. Behavioural intentions of using virtual reality in learning: perspectives of acceptance of information technology and learning style. Virtual Reality 23, 313-324 (2019). https://doi.org/10.1007/s10055-0180348-1

[43] Ngampornchai, A., Adams, J. Students' acceptance and readiness for E-learning in Northeastern Thailand. Int J Educ Technol High Educ 13, 34 (2016). https://doi.org/10.1186/s41239-016-0034-x

[44] Ali, Z., Gongbing, B. \& Mehreen, A. Understanding and predicting academic performance through cloud computing adoption: a perspective of technology acceptance model. J. Comput. Educ. 5, 297-327 (2018). https://doi.org/10.1007/s40692-018-0114-0

[45] Raes, A., Depaepe, F. A longitudinal study to understand students' acceptance of technological reform. When experiences exceed expectations. Educ Inf Technol 25, 533-552 (2020). https://doi.org/10.1007/s10639-019-09975-3

[46] Todaka, K., Kishimoto, J., Ikeda, M. et al. Impact of Risk-Benefit Perception and Trust on Medical Technology Acceptance in Relation to Drug and Device Lag: A Tripartite Cross-Sectional Survey. Ther Innov Regul Sci 52, 629-640 (2018). https://doi.org/10.1177/2168479017739267

[47] Guner, H., Acarturk, C. The use and acceptance of ICT by senior citizens: a comparison of technology acceptance model (TAM) for elderly and young adults. Univ Access Inf Soc 19, 311-330 (2020). https://doi.org/10.1007/s10209-0180642-4

[48] Alharbi S., Drew S. (2019) The Role of Self-efficacy in Technology Acceptance. In: Arai K., Bhatia R., Kapoor S. (eds) Proceedings of the Future Technologies Conference (FTC) 2018. FTC 2018. Advances in Intelligent Systems and Computing, vol 880. Springer, Cham. https://doi.org/10.1007/978-3-030-02686$8 \_85$

[49] Ifedayo, A.E., Ziden, A.A. \& Ismail, A.B. Mediating effect of behavioural intention on podcast acceptance. Educ Inf Technol (2020). https://doi.org/10.1007/s10639-020-10385-z

[50] Klimova B., Poulova P. (2018) Older People and Technology Acceptance. In: Zhou J., Salvendy G. (eds) Human Aspects of IT for the Aged Population. Acceptance, Communication and Participation. ITAP 2018. Lecture Notes in Computer Science, vol 10926. Springer, Cham. https://doi.org/10.1007/978-3-31992034-4_7

[51] Appavoo P. (2021) Acceptance of Technology in the Classroom: A Qualitative Analysis of Mathematics Teachers' Perceptions. In: Satapathy S., Bhateja V., Janakiramaiah B., Chen YW. (eds) Intelligent System Design. Advances in Intelligent Systems and Computing, vol 1171. Springer, Singapore. https://doi.org/10.1007/978-981-15-5400-1_1

[52] Nguyen T.D., Nguyen D.T., Cao T.H. (2014) Acceptance and Use of Information System: E-Learning Based on Cloud Computing in Vietnam. In: Linawati, Mahendra M.S., Neuhold E.J., Tjoa A.M., You I. (eds) Information and Communication Technology. ICT-EurAsia 2014. Lecture Notes in Computer 
Science, vol 8407. Springer, Berlin, Heidelberg. https://doi.org/10.1007/978-3642-55032-4_14

[53] Fan C. (2020) Applied the Technology Acceptance Model to Survey the MobileLearning Adoption Behavior in Science Museum. In: Rau PL. (eds) CrossCultural Design. Applications in Health, Learning, Communication, and Creativity. HCII 2020. Lecture Notes in Computer Science, vol 12193. Springer, Cham. https://doi.org/10.1007/978-3-030-49913-6_23

[54] Lai I.K.W., Lai D.C.F. (2013) Student Acceptance of Electronic Schoolbag Systems: An Empirical Study in China. In: Cheung S.K.S., Fong J., Fong W., Wang F.L., Kwok L.F. (eds) Hybrid Learning and Continuing Education. ICHL 2013. Lecture Notes in Computer Science, vol 8038. Springer, Berlin, Heidelberg. https://doi.org/10.1007/978-3-642-39750-9_31

[55] Pedrotti M., Nistor N. (2016) User Motivation and Technology Acceptance in Online Learning Environments. In: Verbert K., Sharples M., Klobučar T. (eds) Adaptive and Adaptable Learning. EC-TEL 2016. Lecture Notes in Computer Science, vol 9891. Springer, Cham. https://doi.org/10.1007/978-3-319-451534_45

[56] Zefreh M.M., Torok A. (2020) User Acceptance of Driverless Public Transportation: A Questionnaire-Based Study in Budapest. In: Gopalakrishnan K., Prentkovskis O., Jackiva I., Junevičius R. (eds) TRANSBALTICA XI: Transportation Science and Technology. TRANSBALTICA 2019. Lecture Notes in Intelligent Transportation and Infrastructure. Springer, Cham. https://doi.org/10.1007/978-3-030-38666-5_8

[57] Alryalat M.A.A., Rana N.P., Sarma H.K.D., Alzubi J.A. (2016) An Empirical Study of Facebook Adoption Among Young Adults in a Northeastern State of India: Validation of Extended Technology Acceptance Model (TAM). In: Dwivedi Y. et al. (eds) Social Media: The Good, the Bad, and the Ugly. I3E 2016. Lecture Notes in Computer Science, vol 9844. Springer, Cham. https://doi.org/10.1007/978-3-319-45234-0_19

[58] Li Y., Sun J., Yang Y. (2012) Study on E-satisfaction in the Consumer Ecommerce Environment Based on TAM and TTF Extended Model. In: Jin D., Lin S. (eds) Advances in Electronic Engineering, Communication and Management Vol.1. Lecture Notes in Electrical Engineering, vol 139. Springer, Berlin, Heidelberg. https://doi.org/10.1007/978-3-642-27287-5_21

[59] Alshurideh M., Al Kurdi B., Salloum S.A. (2020) Examining the Main Mobile Learning System Drivers' Effects: A Mix Empirical Examination of Both the Expectation-Confirmation Model (ECM) and the Technology Acceptance Model (TAM). In: Hassanien A., Shaalan K., Tolba M. (eds) Proceedings of the International Conference on Advanced Intelligent Systems and Informatics 2019. AISI 2019. Advances in Intelligent Systems and Computing, vol 1058. Springer, Cham. https://doi.org/10.1007/978-3-030-31129-2_37

[60] Geldmacher W., Just V., Grab B., Kompalla A. (2019) Derivation of a Modified Technology Acceptance Model for the Application on Self-driving Cars in a Carsharing-model Based on Qualitative Research. In: Tăchiciu L., Weber G., Bodemann M. (eds) Building Engagement for Sustainable Development. Sustainable Management, Wertschöpfung und Effizienz. Springer Gabler, Wiesbaden. https://doi.org/10.1007/978-3-658-26172-6_12

[61] Alhashmi S.F.S., Salloum S.A., Abdallah S. (2020) Critical Success Factors for Implementing Artificial Intelligence (AI) Projects in Dubai Government United Arab Emirates (UAE) Health Sector: Applying the Extended Technology Acceptance Model (TAM). In: Hassanien A., Shaalan K., Tolba M. (eds) Proceedings of the International Conference on Advanced Intelligent Systems and 
Informatics 2019. AISI 2019. Advances in Intelligent Systems and Computing, vol 1058. Springer, Cham. https://doi.org/10.1007/978-3-030-31129-2_36

[62] Abu Seman A.H., Ahmad R., Alhassan Alhussian H.S. (2020) Factors Influencing Acceptance of Technology by Senior Citizens: A Systematic Review. In: Silhavy R. (eds) Intelligent Algorithms in Software Engineering. CSOC 2020. Advances in Intelligent Systems and Computing, vol 1224. Springer, Cham. https://doi.org/10.1007/978-3-030-51965-0_31

[63] Evans J., Brown M., Coughlan T., Lawson G., Craven M.P. (2015) A Systematic Review of Dementia Focused Assistive Technology. In: Kurosu M. (eds) HumanComputer Interaction: Interaction Technologies. HCI 2015. Lecture Notes in Computer Science, vol 9170. Springer, Cham. https://doi.org/10.1007/978-3-31920916-6_38

[64] Pourfakhimi S., Duncan T., Coetzee W. (2018) A Synthesis of Technology Acceptance Research in Tourism \& Hospitality. In: Stangl B., Pesonen J. (eds) Information and Communication Technologies in Tourism 2018. Springer, Cham. https://doi.org/10.1007/978-3-319-72923-7_12

[65] Tamilmani K., Rana N.P., Dwivedi Y.K. (2017) A Systematic Review of Citations of UTAUT2 Article and Its Usage Trends. In: Kar A. et al. (eds) Digital Nations Smart Cities, Innovation, and Sustainability. I3E 2017. Lecture Notes in Computer Science, vol 10595. Springer, Cham. https://doi.org/10.1007/978-3-319-68557$1 \_5$ 